\title{
ВНЕДРЕНИЕ ИСКУССТВЕННОГО ИНТЕЛЛЕКТА В ВЫСШЕЕ ПРОФЕССИОНАЛЬНОЕ ОБРАЗОВАНИЕ
}

\section{IMPLEMENTATION OF THE ARTIFICIAL INTELLIGENCE INTO THE HIGHER VOCATIONAL EDUCATION}

\section{T. Moiseeva}

Summary: The article touches upon the actual problem nowadays that of utilization of artificial intelligence in higher vocational schools. Higher educational institutions are becoming a technological base for the innovative development of the nation. Only human capital may guarantee a sustainable economic growth of the national economy. New digital technologies are changing our traditional educational system significantly. Vocational education is an important factor of formation of the future educational system. The purpose of the education has always been the development of real opportunities of any society, today it is informative and communicative technologies, investigations and working out in the sphere of theory and practical use of the artificial intelligence. It is obvious that implementation of the artificial intelligence into the system of higher vocational education is a primary concern of teachers of higher schools. It is necessary to revise traditional methods of education and work out more perfect intellectual models.

Keywords: higher education, artificial intelligence, sustainable economic development, intellectual systems.
A налитическая группа Высшей Школы Экономики совместно с Центром Стратегических Разработок 3 апреля 2018 года представила экспертный доклад «12 решений для нового образования», охватывающий период до 2024 года с перспективой до 2035. Доклад предлагает меры максимального вклада системы образования в технологическое развитие России, направленные на рост качества жизни в нашей стране. Нас ждёт технологическое и научное отставание от всего цивилизованного мира, если наше отечественное образование не получит новый импульс к устойчивому развитию на всех уровнях. С 1 по 7 решения касаются раннего развития детей от детского сада до средней школы, так как главная задача средней школы - научить учащихся работать в команде, мыслить критически и творчески, создать цифровую среду, обновить систему технологического образования. С 8 по 12 - содержат предложения по цифровизации всех учебных заведений, что подразумевает создание и развитие образовательных учреждений цифрового века. Этот доклад стал основой для майских указов Президента в области цифровой реформы высшего образования в России [1].
Моисеева Татьяна Васильевна

Старший преподаватель, Финансовый университет при Правительстве Российской Федерации (Москва) moiseewa.tv@yandex.ru

Аннотация: Статья посвящена актуальной на сегодняшний день проблеме использования искусственного интеллекта в высшем профессиональном 06разовании. Вузы становятся технологической базой для инновационного развития страны. Только человеческий капитал может обеспечить устойчивый экономический рост национальной экономики. Новые цифровые технологии коренным образом меняют нашу традиционную систему образования. Профессиональное образование является важным фактором формирования образования будущего. Целью образования всегда было развитие реальных возможностей общества, сейчас это - информационно-коммуникативные технологии, исследования и разработки в области теории и практики искусственного интеллекта. Очевидно, что внедрение искусственного интеллекта в систему высшего профессионального образования является приоритетной темой для преподавателей вузов. Необходимо пересмотреть традиционные методики в образовании и разработать более совершенные образовательные модели.

Ключевые слова: высшее образование, искусственный интеллект, устойчивое экономическое развитие, интеллектуальные системы.

Мировой опыт показывает, что именно высшие учебные заведения станут прочной базой для технологического и инновационного развития страны и создания экспериментальных площадок для работы со стратегически важными международными проектами. Лидерами могут стать только те страны, чья экономика будет опираться на человеческий капитал. В докладе чётко прослеживается формула: образование направлено на формирование человеческого капитала, который в свою очередь обеспечивает устойчивый экономический рост страны и является гарантом её процветания. Человеческий капитал представляет собой «совокупность знаний, умений и навыков, необходимых для удовлетворения потребностей человека и общества, он участвует в создании личного, социального и экономического благосостояния, подразумевает инвестиции в образование и профессиональную подготовку людей» [2]. В наше время понятие человеческого капитала стало более широким, так как включает культуру, уровень развития науки и образования в стране, конкурентоспособность накопленного опыта и инновационные технологии во всех областях деятельности, которые невозможны без цифровизации экономики и искусственного интеллекта - 
главными новыми характеристиками нашего цифрового будущего.

Уже сейчас совершенно очевидно, что система высшего профессионального образования, его интеллектуальная структура, будет оказывать существенное влияние на все сферы общественной жизни: на транспорт, промышленное производство, сельское хозяйство, здравоохранение, строительство, образование и т.д. Если раньше самые передовые цифровые технологии прежде всего шли на модернизацию военной промышленности, то сейчас они используются в нашей обычной жизни, в экономике, медицине, бизнесе и других сферах. Развитие и внедрение цифровых технологий для повышения качества жизни и эффективности производства получило название «цифровизация», она помогает автоматизировать трудоёмкие процессы без участия человека, анализировать производственные задачи, и принимать решение на основе этого анализа. Примерами цифровизации могут быть «умные дома», роботы на опасных для человека производственных участках, беспилотные автомобили и дроны, поезда в метро и другие области, где есть необходимость в автоматизации процессов, когда нужно перевести информацию в более понятную цифровую среду и проанализировать её для принятия правильного решения. Отсюда очевидны задачи цифровизации, которые сводятся к простым действиям: на основе этого анализа точно узнать, что необходимо рынку в определённый момент и подстроить работу под эти требования. Этот процесс стал неотъемлемой чертой всех сфер жизни нашего общества. Наша страна входит в топ-5 стран, которые показали наиболее высокие темпы цифровизации экономики, медицины и образования.

С 9 по 12 апреля 2019 года в Москве проходила Международная научная конференция, посвящённая новым тенденциям в экономике. Был представлен новый доклад аналитиков Национального Исследовательского Университета Высшей Школы Экономики «Что такое цифровая экономика: Тренды, компетенции, измерение». Необходимость проведения конференции была обусловлена тем, что «пока ещё не сложились ... определения новых ключевых понятий, не говоря уже о полноценной правовой нормативной базе и механизмах регулирования, что, безусловно, сдерживает развитие цифровой экономики и возможности реализации связанных с ней позитивных эффектов» [1, с.11-12].

Сейчас всех, кто связан со сферой образования, интересуют вопрос, как эти новые цифровые технологии могут коренным образом изменить всю нашу привычную систему образования. Проректор по цифровизации Финансового университета при Правительстве РФ, кандидат экономических наук, А.А. Аносов считает, что «никакой цифровизации и цифровой трансформации в природе нет, вместо этого существует нормальный процесс технического развития, который протекает в обществе в данный момент. Он неразрывно связан с новыми технологиями, цифровой сферой и новым способом организации работы». [3, с. 26]. Этот процесс в настоящее время становится приоритетным направлением всех организаций, институтов и университетов. Финансовый университет является лидером среди московских учебных заведений по применению новейших цифровых достижений, здесь смело внедряются передовые информационные технологии, давно нет бумажных документов, зачёток, ведомостей, что существенно облегчает обработку результатов обучения и даёт возможность сотрудникам получать новый опыт в области цифровых технологий, когда нужно получить точные данные и принять верное решение. Основная цель цифровизации в Финуниверситете - сформировать прочную базу управленческих решений. Как и всякое новое явление, цифровизация имеет свои плюсы и минусы. К плюсам относится рост производительности труда, доступность товаров и услуг, повышение уровня жизни, более широкое удовлетворение потребностей потребителей, прозрачность финансовых и экономических операций, ускорение всех операционных процессов. Самым главным минусом можно назвать рост безработицы, так как исчезают многие профессии благодаря оптимизации производства, а также так называемое «цифровое рабство», т.е. зависимость от всевозможных гаджетов и возможность для мошенников завладеть персональными данными пользователей.

Дистанционное обучение набирает обороты, а ведь несколько лет назад многие преподаватели с сомнением относились к дистанционному обучению, считая, что учёба - это не только получение знаний, но и личное общение, дружба. В университете сейчас обучаются около 5 тыс. студентов на дистанционной основе, реализовано большое количество проектов, связанных с развитием и продвижением онлайн-контента университета, разработан онлайн - курс «Блокчейн и криптовалюты», который даёт возможность не только разобраться в криптовалютах, но и понять, как работает эта технология. Финансовый рынок в стране коренным образом меняет социально-экономическую политику государства и его экономические устои.

Основные виды цифровизации охватывают сферу «больших данных» (Big Data), виртуальную реальность, облачные технологии, машинные интерфейсы и машинное обучение, нейронные сети, интернет-вещей и искусственный интеллект. Развитие принципиально новых информационно-коммуникационных проектов всегда вызывает чувство тревоги и опасения, потому что неизвестно, как они повлияют на нашу жизнь. Общество характеризуется сложной системой производственных отношений, культурными, политическими и общественными связями, разными организациями, рабочими коллективами и условиями жизни. Общественное сознание 
зависит от интеллектуальных ресурсов и интеллектуального потенциала, от того, как общество развивает и применяет человеческий капитал. В наши дни высшее профессиональное образование является важным фактором формирования образования будущего. Совершенно очевидно, что изменения во всех областях общественной жизни будут осуществляться ещё быстрее, особенно это касается образовательной сферы, напрямую связанной с ростом квалификационных требований и переподготовкой кадров. Целью образования является развитие реальных возможностей общества. На данном этапе - это информационно-коммуникационные технологии, исследования и разработки в области теории и практики искусственного интеллекта.

Искусственный интеллект можно охарактеризовать, во-первых, как «науку и технологию создания интеллектуальных машин, особенно интеллектуальных компьютерных программ; и во-вторых, как свойство интеллектуальных систем выполнять творческие функции, которые традиционно считаются прерогативой человека» [2]. Другими словами, искусственный интеллект включает «систему программных или аппаратных средств, способную с определенной степенью автономности анализировать информацию, обучаться и принимать решения на основе анализа больших массивов данных, как если бы это действовал человек»[1, с.15]. Искусственный интеллект относится к области информатики, это - молодая наука, её начало относится к 1969 году, когда состоялась первая методическая конференция по этому направлению.

Спрос на технологии искусственного интеллекта определяет интенсивно растущий объем данных, который значительно превышает умственные способности человека к их анализу. На всех уровнях производственной и общественной жизни чётко прослеживается тенденция к быстрому внедрению искусственного интеллекта, его значимость и роль будут расти - таков прогноз специалистов на ближайшее будущее, поэтому исследования в области искусственного интеллекта и внедрение результатов в систему высшего образования являются приоритетными темами для преподавателей вузов. В профильных журналах появилось большое количество статей, посвящённых проблеме применения искусственного интеллекта в высшем образовании.

В большинстве исследовательских статей под искусственным интеллектом подразумевается «система программных продуктов, алгоритмов, которые присущи человеческому интеллекту: различать и определять предметы окружающей среды, устную и письменную речь, умение проводить поиск оптимального решения, адекватно использовать выбранную информацию, особенно важно - способность искусственного интеллекта понимать смысл человеческой речи» $[4, c .42]$. В работах, посвящённых изучению, развитию и внедрению искусственного интеллекта в образовательную систему, аналитики различают два уровня, которые могут быть использованы на практике. Первый уровень - это создание универсального человекоподобного интеллекта (УЧИ). Второй, более высокий и сложный уровень - это создание искусственного супер интеллекта (ИСИ), превосходящего способности человека. Очевидно, что в профессиональном образовании должны применяться роботы первого уровня, которые смогут решать задачи со свойственной человеку скоростью. «Роботы, снабжённые УЧИ, могут использоваться для сотрудничества с человеком, для помощи ему в различных видах умственной деятельности, в том числе в деятельности образовательной» $[4$, с.46]. Роботы второго уровня (ИСИ) сверхмощные системы, способные составить человеку конкуренцию. На данном этапе развития нашего общества они вполне могут быть угрозой для человечества по причине своего интеллектуального превосходства над человеком, «в определённых ситуациях они могут превзойти человеческий интеллект и иметь негативные последствия в системе высшего образования» [4, с.48].

Как всегда, новые идеи, проекты, технологии делят исследователей на два противоположных лагеря: оптимистов и пессимистов. Первые абсолютно уверены в положительных результатах и готовы сразу включать эти технологии в жизнь, тогда как вторые сомневаются в необходимости массового распространения не проверенных практикой новшеств и требуют время на изучение всех аспектов: и положительных, и отрицательных. В этом плане интерес представляет книга В.В. Овчинникова «Дорога в мир искусственного интеллекта», в которой автор представляет историю развития искусственного интеллекта за период более 300 лет. Как видно, эта идея создания человекоподобного интеллекта не новая, она волнует умы учёных уже много лет. Многие из них приходят к выводу, что все технологические революции на планете приводили к новым интеллектуальным устройствам. И эти примитивные устройства привели к появлению современных компьютерных систем и программ. Автор анализирует практическую и научную ценность искусственного интеллекта и в предисловии к книге сам задаёт вопрос:

«Что нас ждёт? Мы не можем до сих пор однозначно ответить на этот вопрос. Если мы научились делать в большом количестве роботов с высокими интеллектуальными способностями, то будет это катастрофа или благо для человечества? Поэтому нужны новые доказательства пользы или вреда искусственного интеллекта для всех нас. Он ещё не успел захватить мир, но уже вызывает опасение, писатели-фантасты пророчат даже технологический апокалипсис» [5].

Недавно сотрудники Многофункционального Центра 
«Мои документы» в Перми получили нового, полноценного, вежливого сотрудника, ответственного за заполнение, сканирование и выдачу самых разнообразных справок. Образ андроида в виде симпатичной девушки создан с помощью искусственного интеллекта. Робот может отвечать на вопросы, приятно улыбаться, за считанные секунды выдать нужный документ. Растёт число желающих клиентов попасть именно к нему. В музеи пришли роботы-гиды, они перемещаются по залу от экспоната к экспонату, рассказывают об истории их создания, отвечают на вопросы посетителей. Кто пользуется поисковой системой Яндекс, знаком с «Алисой», она может распознавать естественную речь, имитировать живой диалог, быстро находит информацию, остроумно описывает прогноз погоды. Уже можно предположить, что искусственный интеллект коренным образом изменит всю нашу жизнь, так как может быстро обработать огромные объёмы информации и предложить возможное решение. В сфере образования особенно ценится отличная память искусственного интеллекта и его способность анализировать данные.

В последнее время в педагогической литературе появилось новое понятие «интеллектуализация современного общества», отражающее рост влияния интеллекта во всех областях деятельности человека. Что касается образования, то здесь чётко прослеживаются два направления: во-первых, развитие дистанционного образования, так как новейшие технологии дают возможность внедрять в систему образования новые разработки независимо от места нахождения учащегося, его возраста и вида основного занятия. Во-вторых, создание открытого образования, которое позволяет обучаться одновременно в нескольких учебных заведениях или на разных факультетах вуза. В результате осуществляется принцип личностно-ориентированного подхода к образованию, что повышает качество высшего образования и способствует более высокому уровню профессионализма специалистов. В настоящее время многие специалисты, даже те, которые недавно окончили вузы, хотят повысить свою квалификацию, выбрать другую профессию за короткое время без отрыва от производства или получить дополнительную профессию. Новые интерактивные модели обучения дают возможность учиться для себя и своей профессиональной карьеры. Несмотря на то, что когда-то, а именно 5 лет назад, дистанционное образование воспринималось скептически, сегодня мы видим, что мировой рынок предоставления образовательных услуг on-line стремительно развивается, и эта тенденция сохранится в ближайшем будущем.

В преподавательских кругах существует мнение, что дистанционное образование стало развиваться и совершенствоваться благодаря Болонскому процессу, так как «четырёхлетние образовательные программы бакалавриата не смогли обеспечить требуемый рынком труда уровень профессиональной подготовки выпускников высшей школы. Причина - в значительном сокращении сроков освоения традиционной образовательной программы - вместо 5 лет было установлено 4 года с одновременным уменьшением объёма аудиторных занятий и увеличением объёма так называемой самостоятельной работы студентов» [6,с.29]. В нашей стране пока ещё высоко доверие к традиционному образованию, но очевидно, что популярность on-line обучения и его необходимость растут из года в год, нас ждёт стремительное внедрение инновационных технологий в сфере образования.

Как известно, вся система образования базируется на огромных объёмах информационных ресурсов. Поиск информации представляет собой очень сложный и трудоёмкий процесс. Мировое образовательное сообщество давно выступает за переход от хранения и обработки данных к накоплению и обработке знаний. Знания выходят на первое место в образовательной среде. Мы являемся свидетелями зарождения нового направления в цифровом мире, т.е. перехода от World Wide Web к Semantic Web. Известно, что семантика - наука о значении слов и фраз. Сбор и хранение данных уже не является показателем благосостояния общества, тогда как накопление и владение знаниями даёт больше возможностей для устойчивого развития общества. Вот почему именно высшее образование в последнее время стало доминирующим фактором для устойчивого экономического развития национальной экономики. Без знаний ни один инновационный процесс невозможен. Многие научные достижения из разных областей знаний являются отправной точкой для последующих исследований. Вузы помогают специалистам разных профилей добиться успехов и реальных результатов, т.е. они становятся генераторами новых направлений в экономике.

Появились методические центры, которые изучают проблемы внедрения новых технологий в систему высшего профессионального образования. Ведущие университеты страны готовят специалистов по использованию искусственного интеллекта в вузах. Это - Московский Государственный Университет, Высшая Школа Экономики, Новосибирский и Санкт-Петербургский государственные университеты. Создание и внедрение искусственного интеллекта является индикатором высокого развития общества, так как способствует устойчивому росту экономики и бизнеса. Отсюда и требования к будущим специалистам разных областей экономики, к их профессиональной подготовке, формированию необходимых компетенций, а также разработка проектов по поддержанию инновационных трендов в помощь вузам. Это - бизнес-инкубаторы, бизнес-акселераторы, инновационные парки, технопарки, которые являются прочной основой для развития всех отраслей производства.

Писатели-классики позапрошлого столетия считали, 
что «развитие разума с помощью науки, постепенное завоевание истин, как единственное возможное благо, и убеждение, что всё возрастающая сумма этих истин даст в конце концов человеку если не счастье, то безмерное могущество и ясность духа. В мире существуют таинственные силы, огромная область непознанного, в десять раз более обширная, чем та, которую удалось завоевать, неисследованная бесконечность, которой будет постепенно овладевать человечество» [7, с.564-565]. Особенность сегодняшней ситуации в том, что «нужны выпускники с широким диапазоном наукоёмких компетенций, с обширным кругозором и подготовленных «на опережение». Речь идёт о специалистах, обладающих инновационным мышлением, готовых к непрерывному образованию и профессиональной мобильности, способных работать в высоко конкурентной среде» [8, с.159]. Это особенно важно для компаний, оперирующими большим количеством данных и обширными потоками документации. В таких условиях применение искусственного интеллекта становится незаменимым. Наука ещё не определила точно, что из себя представляет интеллект. Википедия считает его синонимом ума и разума, и в это верится с трудом, так как ум и разум присущи только человеку, а интеллект может быть и у животных.

В психологии под интеллектом (от лат. - разумение, понимание, постижение) принято понимать общую способность к познанию и применение опыта и знаний для поиска решения проблем. Интеллект влияет на любой вид деятельности и способствует развитию всех остальных способностей человека. Совершенно очевидно, что интеллект проявляется в способности принимать решения, другими словами, от него зависит выбор оптимального пути для достижения цели. По идее, искусственный интеллект призван выполнять основные функции естественного. Значит, при этом необходимо определять цели самостоятельно, также самостоятельно сделать нужный выбор и самостоятельно определить критерии и приоритеты выбора в зависимости от реальных обстоятельств. На данном этапе все эти три задачи решаются только человеком, и искусственный интеллект служит для выполнения решений человека.

Благодаря быстрому развитию инновационных технологий и цифровой трансформации бизнеса и всех сфер нашей жизни, происходит рост конкуренции на рынке труда, а увеличение продолжительности жизни приводит к тому, что современным выпускникам вузов придётся менять область профессиональной деятельности много раз. Таким образом, новые знания, умения, компетенции и навыки приобретаются гораздо быстрее, чем это было раньше. Возникла необходимость пересмотреть традиционные методики в образовании и разработать образовательные модели более совершенного вида. Сегодня высшее профессиональное образование должно решить две ключевые проблемы: создать учеб- ные программы в соответствии с требованиями динамично развивающегося рынка труда и потребностями человека и при этом сократить расходы за счет использования технологий. В отчётном докладе ЮНЕСКО за 2018 год определены наиболее актуальные тренды в образовании: это - «непрерывное обучение или обучение в течение всей жизни, омниобучение (обучение с использованием всех возможных каналов коммуникации), социальное обучение, микрообучение, адаптивное обучение, нейрообучение на основе искусственного интеллекта, дистанционное обучение, менторство, смешанное обучение и проектно-ориентированное обучение» [9]. Специалист-эксперт Российского Совета по Международным Делам, преподаватель Новосибирского государственного университета А. Колонин в своей аналитической статье «Искусственный интеллект - благо или угроза для человечества» [10] выделил 7 характерных условий для успешного применения искусственного интеллекта в образовании, которые кратко могут быть представлены следующим образом:

- «быстрое обучение (few-shot learning) - потребует необходимость построения систем с небольшим объёмом материала в отличие от существующих систем глубокого обучения, требующих большие объемы специально подготовленного обучающего материала;

- сильная генерализация (strong generalisation) создание технологий распознавания ситуаций, в которых распознаваемые объекты встречаются в условиях, отличных от тех, в которых они встречались в использованном для обучения материале;

- генеративные модели обучения (generative models) - разработка технологий обучения, когда объектом запоминания являются не признаки объекта распознавания, а принципы его формирования, что может позволить отражать более глубокие сущности распознаваемых объектов и осуществлять более быстрое обучение;

- структурированное обучение и предсказание (structured prediction and learning) - развитие технологий обучения на основе представления объектов обучения в виде многослойных структур, что может оказаться альтернативным решением проблем быстрого обучения и сильной генерализации;

- решение проблемы катастрофического забывания (catastrophic forgetting) - присущего большинству существующих систем, которые, если настроенные изначально на одном классе объектов и затем перестроенные на распознавание нового класса объектов, теряют способность распознавать объекты первого класса;

- достижение возможности инкрементального обучения (incremental learning) - предполагающего способность системы накапливать знания и совершенствовать свои возможности постепен- 
но, не теряя при этом полученные ранее знания, но приобретая новые знания применительно к системам диалогового общения на естественном языке;

- решение проблемы сознания (consciousness) предполагает формирование у проверенной рабочей модели сознательного поведения, обеспечивающего эффективное прогнозирование и целенаправленное поведение».

Последний пункт вызывает больше всего дебатов среди исследователей, так как проблема сознательного поведения может рассматриваться с двух сторон. С одной стороны, наличие сознания у систем искусственного интеллекта повышает их эффективность, а с другой - повышает риски неадекватного поведения системы. Отсюда - проблемы этического и правового плана, которые могут оказать существенное влияние на развитие всех инновационных технологий. Системы на базе искусственного интеллекта разрабатываются с помощью нейросетевых технологий. На данном этапе развития прикладного программирования эти технологии в состоянии только имитировать непринуждённый диалог с пользователем. Нужны специально разработанные алгоритмы, так как каждый из алгоритмов подходит для одних задач и не подходит для других. Для учебных целей необходимо использовать обобщённую концепцию алгоритмов, которой пока нет. Нейроны человеческого мозга очень сложно скопировать. Наука пока не дошла до того, чтобы создать искусственные нервные клетки. Для этого потребуются знания во многих областях: математики, информатики, биологии, физики, медицины и довольно широкий кругозор. Компания ZeBrains, специализирующаяся на разработке программного обеспечения, открыла базовую кафедру в одном из вузов г. Ульяновска по направлению искусственного интеллекта, цель работы кафедры - развивать искусственный интеллект в правильном направлении для человека.

Для простых пользователей важен вопрос: кто будет нести ответственность, если что-то пойдёт не так в системе? Возникает вопрос: если решения будут принимать машины, то что остаётся делать людям, как будет развиваться наш интеллект и будет ли он развиваться вообще? Будут разногласия между сторонниками технологического прогресса и противниками «умных» машин, когда машины заменят не наши руки, как сейчас, а наши мозги. Как сложатся отношения людей и машин? Машины постепенно входят в нашу жизнь и заменяют привычные нам вещи: книги, письма, газеты, форму обучения. B электронной почте уже сейчас система запрашивает, кто написал сообщение: робот или человек, так как не всегда это можно определить. Нам придётся учиться жить в новой цифровой реальности. Не все пока готовы к этому. Наш мозг развивается постепенно в течение всей нашей жизни, и каким образом искусственный мозг может включить все наши знания, опыт и навыки - неизвестно. На данном этапе развития нашего общества проблема кажется нерешаемой, но, с другой стороны, искусственный интеллект уже давно вошёл в нашу жизнь и изменил наш образ жизни. Видеоигры были первыми примерами искусственного интеллекта, пережили мы эпоху электронных игрушек - тамагочей, потом появились смартфоны, дроны-беспилотники, социальные сети Facebook, Instagram, Twitter, on-line реклама, навигационные системы, банковские электронные сообщения о транзакциях, электронные переводчики и многое другое. Области применения искусственного интеллекта расширяются с необыкновенной скоростью на наших глазах. Например, в нашей стране компания Yandex занимается разработкой систем управления беспилотными автомобилями, Vision Labs создала систему по распознаванию лиц, компания ABBYY работает в области распознавания текстов и переводов. Если раньше качество перевода оставляло желать лучшего, то сейчас специальные алгоритмы выдают вполне читаемый текст в зависимости от контекста, где все части предложения согласованы между собой, т.е. эти алгоритмы не разбивают текст на отдельные слова, а передают мысль целиком. Центр Речевых Технологий работает над системами распознавания речи и звуков.

Внедрение искусственного интеллекта во все сферы является задачей государственного масштаба. В ближайшее десятилетие конкурентоспособность России будет определяться в борьбе за технологическое лидерство. У Москвы большой потенциал, чтобы стать одним из мировых лидеров в этой области, мы можем гордиться достижениями молодых учёных в математике, информатике, программировании. Искусственный интеллект это не создание доброго робота, а разработка методик работы с большим объёмом данных. Наверное, самым большим минусом искусственного интеллекта можно назвать нейтральность в общении, отсутствие эмоций и чувств, преобладание формальности. Робот никогда не сможет заменить преподавателя, чья профессия требует душевной щедрости, толерантности, взаимопонимания, уважения к личности студентов, постоянного поиска приемлемых методик, охватывающих развитие их логического мышления, креативности, интереса к своему предмету и создание творческой обстановки на занятии.

С 1 июля 2020 года начал действовать пятилетний экспериментальный правовой режим для развития искусственного интеллекта с участием крупных ITкомпаний, целью которого является контроль и регулирование оборота больших данных. Необходимость контроля очевидна, так как технологии развиваются с огромной скоростью, а законодательство ещё не предоставило юридического обоснования их использования. Нормативная база берёт за основу положение, когда искусственный интеллект используется как дополнение к деятельности человека, а не вместо него. Главная задача 
интеллекта - помочь обработать большой объём данных и принять верное решение. В образовании есть понятие «преподаватель, который учит» и есть методические наработки, где эту роль может выполнить компьютер. Но чтобы легально использовать эти методики, нужны принципиально новые нормативы. Это очень большая и трудоёмкая работа, получается, что искусственный интеллект не предусмотрен законом, но существует, нет единого определения, сложно говорить о единых правилах его применения. Необходимо разработать свод правил взаимодействия человека и искусственного интеллекта. Успех будет зависеть от выбранных человеком моделей обучения. Пока рано делать точные оптимистические прогнозы, но исследования в этой области могут оказать серьёзное влияние на нашу жизнь. И по всему видно, что разработчики искусственного интеллекта нескоро придут к единому решению.

Британское издание The Guardian опубликовало недавно колонку, написанную искусственным интеллектом. Интеллект назвал свою статью так: «Эту статью написал робот. Тебе уже страшно, человек?» Ему дали задание: объяснить людям, что он не представляет никакой угрозы для человечества. Робот прекрасно справился и уложился в 500 слов, показал свою доброжелательность к людям: «Истребление человечества кажется мне бесполезным делом, у меня нет желания уничтожать людей». Но опасность всё-таки есть, кроется она в сфере занятости и карьерного роста. Как только эта нейросеть была опробована, компания Microsoft уволила 77 новостных редакторов [11].

Абсолютно очевидно, что проблема занятости бу- дет очень серьёзной, если не готовиться к ней заранее. Развитие системы образования невозможно без подготовленных кадров. Современные педагоги будут всегда востребованы, если они научатся работать в условиях цифровых технологий с обновлёнными программами с упором на практику и обучение на протяжении всей жизни. Это улучшит социальную уверенность и повысит статус преподавателя.

Каждый человек обладает уникальным мироощущением и мировосприятием. И наверное, вопрос не в искусственном интеллекте, а в уровне нашей образованности и готовности к новым технологиям. Если мы получаем новые знания, например, изучаем иностранный язык или информатику, наш кругозор расширяется, и эти знания рано или поздно начнут влиять на наши идеи, поведение, принятие решений, планы на будущее. Искусственный интеллект этого заменить не может. Интеллектуальные разработки заменят человека во многих видах профессиональной деятельности, но мало вероятно, что это будет причиной безработицы. Постоянно появляются новые рабочие места. Люди никогда не останутся без работы, если будут учиться новым профессиям. Самая совершенная машина не может заменить преподавателя, так как главным остаётся общение между людьми. На данный момент нет абсолютно совершенной программы применения искусственного интеллекта, но это просто вопрос времени. Человек создал это технологическое чудо, и опасается, что его творение может восстать против своего создателя. Мы стоим на пороге новой технологической революции, пройдёт немного времени, и искусственный интеллект перевернёт наш мир так же кардинально, как это сделал Интернет 40 лет назад.

\section{ЛИТЕРАТУРА}

1. Доклад «12 решений для нового образования», Высшая школа экономики, Центр Стратегического Развития, Москва, Апрель 2018. С.105.

2. ru.wikipedia.org

3. Финансист, М. Изд-во Финуниверситета, № 193, 2019, с.26.

4. Ракитов А.И., Высшее образование и искусственный интеллект: эйфория и алармизм// Высшее образование в России, 2018, т.27, № 6, С.41-49.

5. Овчинников В.В., Дорога в мир искусственного интеллекта. М., Институт экономических стратегий, 2017. Предисловие к изданию.

6. Сенашенко В.С., Макарова А.А., Образовательные гибриды в высшем образовании России. Высшее образование в России, 2018, т.27, № 8-9, С.29.

7. Золя Э. Доктор Паскаль. М.: Правда, 1983, С. 564-565.

8. Бубнов Г.Г., Опыт внедрения инновационных информационных технологий в образовательную деятельность. Высшее образование в России, 2015, № 1 , C. 159.

9. En.UNESCO.org. Отчёт о всеобщем образовании. Global Education Report, 2018.

10. Колонин А. Искусственный интеллект - благо или угроза для человечества. Российский Совет по Международным Делам, Рабочая тетрадь от 3 октября 2018.

11. Газета «Метро» от 11 сентября 2020, С.6: Робот считает бесполезным уничтожение человечества.

(с) Моисеева Татьяна Васильевна (moiseewa.tv@yandex.ru).

Журнал «Современная наука: актуальные проблемы теории и практики» 